\title{
Physician and Patient Behavior
}

\section{Time Allocation in Primary Care Office Visits}

\author{
Ming Tai-Seale, Thomas G. McGuire, and Weimin Zhang
}

Objectives. To use an innovative videotape analysis method to examine how clinic time was spent during elderly patients' visits to primary care physicians. Secondary objectives were to identify the factors that influence time allocations.

Data Sources. A convenience sample of 392 videotapes of routine office visits conducted between 1998 and 2000 from multiple primary care practices in the United States, supplemented by patient and physician surveys.

Research Design. Videotaped visits were examined for visit length and time devoted to specific topics-a novel approach to study time allocation. A survival analysis model analyzed the effects of patient, physician, and physician practice setting on how clinic time was spent.

Principal Findings. Very limited amount of time was dedicated to specific topics in office visits. The median visit length was 15.7 minutes covering a median of six topics. About 5 minutes were spent on the longest topic whereas the remaining topics each received 1.1 minutes. While time spent by patient and physician on a topic responded to many factors, length of the visit overall varied little even when contents of visits varied widely. Macro factors associated with each site had more influence on visit and topic length than the nature of the problem patients presented.

Conclusions. Many topics compete for visit time, resulting in small amount of time being spent on each topic. A highly regimented schedule might interfere with having sufficient time for patients with complex or multiple problems. Efforts to improve the quality of care need to recognize the time pressure on both patients and physicians, the effects of financial incentives, and the time costs of improving patient-physician interactions.

Key Words. Visit length, patient-physician interaction, quality of care, clinical practice pattern, primary care

Time is a scarce resource in a physician's office practice. How physicians use clinic time has important implications for quality of care, patient trust (Fiscella et al. 2004), malpractice suits (Levinson et al. 1997), and is one of the bases of physician payments (Hsiao et al. 1988). Mechanic, McAlpine, and Rosenthal (2001) reported that the average length of a physician visit had increased from 
16.3 to 18.3, between 1989 and 1999, based on survey data from the National Ambulatory Medical Care Survey (NAMCS) and the Socioeconomic Monitoring System (SMS). Data from direct observation of primary care office visits by nurse researchers called into question these results, however. Yawn et al. (2003) found that primary care physician office visits lasted about 10 minutes. Further, Gilchrist et al. (2004) found physicians or their office staff over-reported visit length by almost 4 minutes when completing the NAMCS encounter forms.

Patient-physician conversations are complex, multidimensional, and multifunctional (Mishler 1984). Visits vary not only in length but also in the division of time among topics. Patients typically present multiple complaints during an office visit requiring physicians to divide time and resources during a visit to deal with competing demands. A unique and critical role of primary care physicians has been to provide patients with an "advanced medical home" where complex comorbidities are diagnosed and treated. Braddock et al. (1999) analyzed audiotapes of office visits to primary care physicians and surgeons and reported a median of three patient concerns per visit. Beasley et al. (2004) reported an average of 3.9 concerns discussed with elderly patients by family physicians. Studying how physicians use clinical time through examining the contents of the visit is also important to illuminate the process of care (Donabedian 2005). Our review of the literature (Hsiao et al. 1988; Charon, Greene, and Adelman 1994; Thompson et al. 2003; Heritage and Maynard 2006) and personal communications with other researchers lead us to believe that this study is the first to directly measure the actual amount of time spent by patients and physicians on topics occurring during office visits.

In this paper, we took advantage of a unique data set consisting of videotaped elderly patients' visits with their primary care physicians in three distinct organizational settings: salaried group practice in an academic medical center, a managed care group (MCG) practice, and fee-for-service inner city solo (ICS) practitioners with an Independent Practice Association contract. We examined not only the length of visits, but more importantly, the content of visits in terms of units of clinical decision making we refer to as "topics," operationalized as

Address correspondence to Ming Tai-Seale, Ph.D., M.P.H., Department of Health Policy and Management, School of Rural Public Health, 1266 TAMU, College Station, TX 77843-1266. Dr. Tai-Seale, Association Professor, is with the Department of Health Policy and Management, Texas A\&M Health Science Center School of Rural Public Health, College Station, TX. Thomas G. McGuire, Ph.D., Professor, is with the Department of Health Policy and Management, Harvard Medical School, Boston, MA. Weimin Zhang, Ph.D., is with the Department of Statistics, Texas A\&M University, College Station, TX. 
clinical issues raised by either participant. Our approach was in the spirit of the multidimensional interaction analysis (MDIA) system, which codes an interaction directly from an audiotape of the visit based on topics sequentially introduced by patient or physician. The MDIA lists 36 categories subdivided into five major content areas: biomedical, personal habits, psychosocial, patient-physician relationship, and other (Charon, Greene, and Adelman 1994). We partitioned a visit into similar topics, and took a step further by recording the amount of time spent on each topic by patient and physician. Our approach allows us to examine how much time is dedicated to specific topics, and the factors that influenced how clinical time is allocated.

This paper addresses a series of questions about visits and topics within visits. First, what was the length of a primary care office visit for these elderly patients? Second, how many topics were discussed, and how much time was devoted to each topic? Third, what were the topics of discussion and how did the length of time speaking by patient and physician vary across different types of topics? Lastly, we analyze the influence of patient, physician, and physician's practice setting characteristics on how clinic time was spent using duration (or survival) analysis. Our main goal is to characterize physician-patient encounters in a new way, in order to study how physicians and patients allocate the scarce resource of physician time to deal with the complex set of problems arising in an office visit.

\section{DATA AND METHODS}

This paper conducts analyses of videotapes collected for another study based on a convenience sample of office-based physicians and their patients in three types of practices (Cook 2002). The practices included a salaried medical group as part of an Academic Medical Center (AMC) in the Southwest, a managed care group (MCG) in a Midwest suburb, and a number of fee-forservice inner city solo (ICS) practitioners in a Midwestern city. These sites were chosen to include diverse practice forms and representation of patients and physicians from racial minority groups.

\section{Participants}

The recruitment effort resulted in a sample of 35 physicians, all of whom had completed their training at the time of the initial study. Patients had to be at least 65 years of age to be eligible for the original study, identify the participating physician as their usual source of care, and provide informed consent. 
Specifically, patients were identified from their primary care physicians' patient panels provided by office managers of the participating clinics. When these patients came to the participating clinic for a visit, regardless of the nature of the visit (e.g., acute upper respiratory infection, or for routine checkup for diabetes or hypertension), they were invited to participate in the study. If they expressed willingness to participate, informed consent was obtained and their visits were taped. Patient participation rates ranged from 61 to 65 percent at the three sites. The final sample contained 392 videotaped visits. ${ }^{1}$ Details of participant recruitment have been reported elsewhere (Tai-Seale et al. 2005).

Compared with national data (American Medical Association 2001), our physician estimation sample is similar in gender composition but has fewer physicians in the extremes of the age distribution. African-American physicians were overrepresented in our data (14 percent, compared with 6 percent nationally). Our patient sample is similar to national data on elderly patients in age distribution, and living arrangement (U.S. Census Bureau 2001) but different in having more educated and fewer married patients (Federal Interagency Forum on Aging Related Statistics 2000).

\section{Videotape Coding}

Coding of the videotaped visits consisted of four major components: identifying topics, determining the talk time, coding the dynamics of the talk, and recording additional measures. See Appendix A for details on training of the coders.

Identifying Topics. Coders first carefully reviewed the entire video to determine the nature and number of topics raised during the visit. Following the MDIA grouping (Charon, Greene, and Adelman 1994), a topic was regarded as an issue that required a specific response by the physician or patient. Each patient-raised symptom was treated as a topic unless the patient connected the symptoms within a "common sense" grouping, if so, the grouping was treated as a topic. An example could be that a patient talked about coughing and headache. He mentioned them one after another and indicated his worry about having bronchitis. Applying common sense about upper respiratory infections, the patient had grouped the symptoms of cough and headache together. Rather than coding two separate topics of cough and headache, we combined them into one topic labeled "worried about bronchitis." 
Figure 1: Flow of Conversation during a Visit

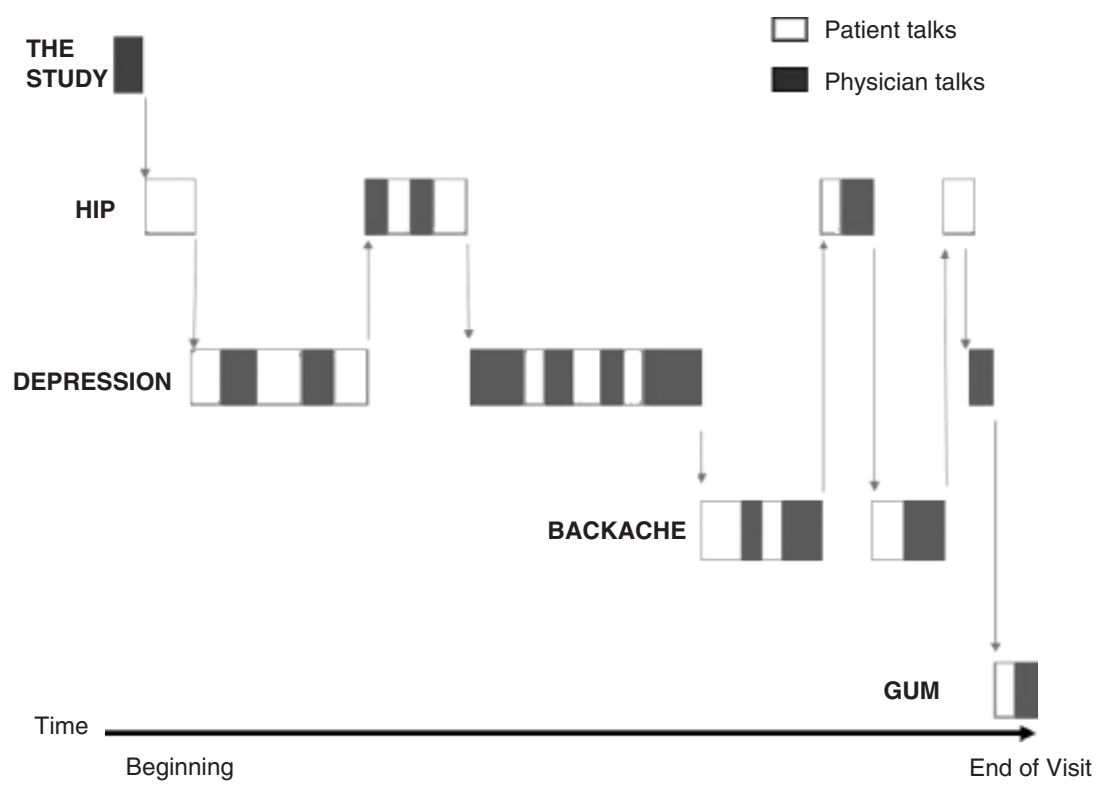

As mentioned earlier, the MDIA has 36 topics and five major content areas. In recognition of the prevalence of depression, anxiety, and other mental illnesses treated in primary care, we formed a mental health content area, which is a subset of the psychosocial content area in the MDIA. We identified 36 topics pertaining to six major content areas: biomedical, mental health, personal habits, psychosocial issues, patient-physician relationship, or other topics. Each topic was assigned a number from a predetermined list of 36 topics (Charon, Greene, and Adelman 1994).

Figure 1 depicts the flow of conversation during one office visit in the data and illustrates how this is grouped into topics for coding. The visit started with the physician noting the camera upon his arrival: "They want to see how I talk to my patients." The patient smiled and started to tell the physician about her status after the hip fracture. She then told the physician that she had been depressed. The physician empathized by stating that a lot had happened since the death of her husband. She recounted the days preceding her husband's death and her son's reaction to his death. The doctor brought the topic back to her hip. He reviewed the pain medications prescribed for her 
hip pain (Propoxyphene), and then the antidepressants (Paroxetine and Amitriptyline) that she was taking. She expressed concern over "sleeping too much" and questioned if the medicines were "too strong." The physician told her that he thought that she was doing just fine and he would not change the medications. He then directed the conversation to her backache. During the course of the discussion on backache, they revisited the hip fracture topic. Lastly, they briefly discussed her gum ache and dentures. After reviewing this encounter, the coders detected five topics: (1) the study, (2) status of hips, (3) depression, (4) backache, and (5) gum pain. The discussion about her husband's death was brought up and addressed within the context of her depression. Therefore, conversations on his death were counted in the depression topic.

Talk Time and Topic Length. Patient talk time was measured as the length of time the patient spent talking before discussion of the topic concluded. Talk time of a patient's companion if present at the visit was included in patient's talk time. Physician talk time was defined as the length of time the physician spent talking before the topic concluded. As the two took turns talking, each person's talking time before the other started talking was recorded and then added to get the total length of time each person spent talking. Topic length is measured by the sum of the time-in either talking or in silence as long as both patient and physician are in the room-that elapsed between the beginning and the end of all instances of a topic. The sum of the talk time by the patient and physician may be less than the total topic length because at times, both parties sat in silence, ${ }^{2}$ the physician viewing or writing in the chart. Figure 1 illustrates how the time variables are coded.

Verbal or Nonverbal Cues. The coders were trained to record uncertainty and verbal or nonverbal cues of emotional distress during discussions of each topic. Expression of uncertainty was indicated by statements that conveyed the idea that the speakers were not sure about the accuracy of their statements (Gill 1998). Hesitations and words or phrases such as, "we don't know ..." "may," "might," "is it true that ...," and speculative expressions such as "it may be true that ..." were taken to suggest uncertainty. Vocalized pauses, which are the ums, uhs, and ahs, the spoken equivalents of throat clearing and false starts, that exist in one's speech (Wilson 1993), were also taken into account in coding uncertainty. The coders were reminded to pay close attention to the context in which these expressions were uttered to distinguish expression of uncertainty from expression of politeness (Gill 1998). 
Verbal cues of emotional distress included expressions such as "I'm such a basket case," "What else is there to live for?" Nonverbal cues of emotional distress include depressed face, downward gaze, self-touching, drooping posture, and slowed speech (suggesting depression) or fidgety hands, darting eyes, and a still upper body (suggesting anxiety) (Gattellari et al. 2002; Eide, Graugaard, and Finset 2004; American Psychiatric Association 1994). Two binary variables record whether the patient showed either cue while discussing each topic. Because of their correlation, we only included nonverbal cues in the regression analysis.

Survey Data. Surveys of patients and physicians complement the video data. Variables from the surveys were chosen for analysis based on research about how patient-physician interaction is influenced by patient health (Bertakis et al. 1993), gender and race (Roter, Hall, and Aoki 2002; Balsa, McGuire, and Meredith 2005), education (Waitzkin 1985), and physician gender (Roter, Hall, and Aoki 2002; Roter and Hall 2004). Patient's health status was measured by normed SF-36 scores (Ware, Kosinski, and Dewey 2000). The length of the patient-physician relationship was measured by the number of years the patient had seen the physician (Waitzkin 1985).

\section{Empirical Specification}

Topic and visit-level analyses were conducted separately to describe the length of time spent and the determinants of time at both levels. At the topic level, our data contain multiple observations (i.e., topics) for each patientphysician dyad (visit). We used mixed-level data methods to account for the clustering at the dyad level. The dependent variables were patient talk time, physician talk time, and topic length. At the visit level, the dependent variables were visit length, total patient talk time, and total physician talk time.

We used a survival model to analyze the likelihood that the topic or visit would end, given how much time had already been spent on it. To test duration dependence, we use the Weibull proportional hazard function (Cleves, Gould, and Gutierrez 2004). At the topic level

$$
h\left(t \mid \mathbf{x}_{i}\right)=h_{0}(t) \exp \left(\boldsymbol{\beta}^{\prime} \mathbf{x}_{i}\right)
$$

where $t$ is time in seconds; $\boldsymbol{\beta}^{\prime}=\left(\beta_{1}, \ldots, \beta_{j}, \ldots, \beta_{j}\right)$ is a parameter vector for covariates. $\mathbf{x}^{\prime}{ }_{i}=\left(x_{i 1}, \ldots, x_{i j}, \ldots, x_{i}\right)$ is a data vector; $\mathbf{x}_{i}$ represent topics, $i=1$, $\ldots, K$ where $K$ is the total number of topics; $j=1, \ldots, J$ is the index for explanatory variables which included: topic (biomedical, personal habits, 
mental health, psychosocial, patient-physician relationship, and other issues topic; patient initiation; physician showed uncertainty, patient showed uncertainty, patient showed mood problem nonverbally), site (AMC, MCG, and ICS), patient (age, gender, health status, and education), physician (gender), patient and physician dyad (years patient has seen this physician). (AfricanAmerican patients and physicians were concentrated in the ICS preventing us from conducting an analysis of race of patient or physician separate from site.)

Therefore, $x_{i j}$ represents the explanatory variable's value for topic $i$ and explanatory variable $j$. In equation $(1), h_{0}(t)$ is the baseline hazard rate which can be modeled as

$$
h_{0}(t)=s t^{s-1} \exp \left(\beta_{0}\right)
$$

where $s$ and $\beta_{0}$ are parameters to estimate. $s$ is known as the shape parameter which represents the presence of duration dependence if it is different than 1 . $\beta_{0}$ is a scale parameter in the Weibull model. Interpretation of coefficients in the Weibull model as hazard ratios $(\mathrm{HR})$ is not straightforward. We evaluate the quantitative relationship between a change in covariates and the change in length of time at a constant survival probability. We can then calculate the percent change in talk time as a result of an increment in an explanatory variable, (the steps are shown in Appendix B) which is

$$
\text { Percent change in talk time }=\left(t_{1}-t_{0}\right) / t_{0}=t_{1} / t_{0}-1=\mathrm{HR}^{-1 / s}-1 .
$$

Equation (3) enables us to calculate, holding constant the survival probability, how changes in key explanatory variables would influence the length of time spent on a topic or a visit.

For the topic level analysis, the nature of the topic was captured by five binary variables representing the major content areas, with biomedical topic as the comparison group. Additional variables include binary variables for initiator of the topic, physician showing uncertainty, patient showing uncertainty, patient showing cue of mood problem nonverbally.

For the visit level analysis, we examined the effects of visit content complexity on talk times. Complexity was measured by the percent of time spent on each of the six groups of topics out of total talk time. ${ }^{3}$ In constructing a measure for patient initiation, we created a variable for the share of the topics in all of the topics in the visit that were initiated by the patient. A similar approach was used to create variables for the share of topics in which the physician had shown uncertainty, and the share of topics in which nonverbal cues of mood problems were observed in the patient. Analyses were performed in STATA, version 9 (STATACorp 2003). 


\section{RESULTS}

The 392 videotaped visits contained 2,557 topics which represented all of MDIA topics with the exception of elder abuse which was not present in our sample. Of those topics, 77 percent of the topics $(1,977)$ were discussed with 27 male physicians whereas 23 percent of them (580) were discussed with eight female physicians.

\section{Univariate and Bivariate Analyses}

Average length of visits was 17.4 minutes. The median length of visits was 15.7 minutes. The median talk time by patient was 5.3 minutes, and physician, 5.2 minutes. The median time during which neither part spoke was 55 seconds. (Note: unlike the case of the mean, the sum of the medians is not the median of the sum.) The average number of topics in a visit was 6.5 (median $=6$, minimum $=1$, maximum $=12$; Table 1 ). Owing to the skewness of time variables, we report the medians in descriptive statistics.

We separated out the longest topic (which will be called the "major" topic) from the rest of the topics, which we will call "minor" topics. We noticed a significant reduction between the time spent on major (5.25 minutes) and minor topics. During major topics, patients talked for 2.03 minutes and physicians, 2.31 minutes. The minor topics received 1.1 minutes during which patients spoke for half a minute and physicians, 0.4 minute per topic (Table 1).

Bivariate analyses show that, in comparison with 23.3 minutes spent at the AMC, the length of visit were significantly shorter at the MCG practice (13.4 minutes, $p<.01)$ and the inner city solo practices (ICS; 9.7 minutes, $p<.01)$. Patients at the MCG (4 minutes, $p<.01)$ and ICS (1.8 minutes, $p<.01)$ spoke significantly less than patients at the AMC (8 minutes). Physicians at the MCG also spoke much less $(4.7$ minutes, $p<.01)$ than their colleagues at the AMC (5.9 minutes). ICS physicians spoke less than half (2.6 minutes, $p<.01)$ as much as AMC physicians. Among the major topics, patients at the AMC spoke significantly longer (3.0 minutes) than patients at the MCG (1.7 minutes, $p<.01)$ and ICS $(0.9$ minutes, $p<.01)$. Similar patterns existed for topic length but not for physician talk time. It is possible that the manner in which physicians at the MCG and ICS spoke signaled patients to limit their "air time." The pattern persisted when time was examined across minor topics (Table 1).

The majority of topics (72 percent) pertained to biomedical issues whereas mental health topics composed 2.9 percent. Seven percent of the topics were devoted to personal habits. Twelve percent of topics were about psychosocial matters. Discussion of the patient-physician relationship ac- 
Table 1: Descriptive Statistics by Practice Settings

\begin{tabular}{|c|c|c|c|c|}
\hline & $\begin{array}{c}\text { Total } \\
\text { Sample }\end{array}$ & $\begin{array}{c}\text { Academic } \\
\text { Medical } \\
\text { Center }\end{array}$ & $\begin{array}{c}\text { Managed } \\
\text { Care } \\
\text { Group }\end{array}$ & $\begin{array}{c}\text { Inner } \\
\text { City Solo } \\
\text { Practice } \\
\end{array}$ \\
\hline \multicolumn{5}{|l|}{ Median time length (minutes) } \\
\hline \multicolumn{5}{|l|}{$\operatorname{Visit}(N=392)$} \\
\hline Patient talk time & 5.3 & 8.0 & $4.0^{* * *}$ & $1.8^{\text {*** }}$ \\
\hline Physician talk time & 5.2 & 5.9 & $4.7^{* * *}$ & $2.6^{\text {*** }}$ \\
\hline Visit length & 15.7 & 23.3 & $13.4^{* * *}$ & 9.7 *** \\
\hline \multicolumn{5}{|l|}{ Major topic $(N=392)$} \\
\hline Patient talk time & 2.0 & 3.0 & $1.7^{* * *}$ & $0.9^{* * *}$ \\
\hline Physician talk time & 2.3 & 2.4 & 2.3 & 1.7 \\
\hline Topic length & 5.3 & 6.7 & $4.8^{* * *}$ & $3.2^{* * *}$ \\
\hline \multicolumn{5}{|l|}{ Minor topics $(N=2,059)$} \\
\hline Patient talk time & 0.5 & 0.7 & $0.4^{* * *}$ & $0.2^{* * *}$ \\
\hline Physician talk time & 0.4 & 0.5 & $0.4^{* * *}$ & $0.3^{* * *}$ \\
\hline Topic length & 1.1 & 1.4 & $0.9 * *$ & $0.7^{* * *}$ \\
\hline \multicolumn{5}{|l|}{ Patient characteristics $(N=385)$} \\
\hline Mean age in years & 74.3 & 75.3 & 73.8 & 73.4 \\
\hline$\%$ Female & 66.8 & 67.7 & 65.5 & 71.9 \\
\hline$\%$ White & 81.3 & 73.9 & $96.5^{* * *}$ & 0 *** \\
\hline$\%$ African American & 10.3 & 2.3 & $2.6^{* * *}$ & $100 * * *$ \\
\hline Education, $\%$ college or more & 44.4 & 56.2 & $40.2 * *$ & $25.8 * *$ \\
\hline Mean SF36 physical role functioning & 38.5 & 36.5 & 39.2 & 41.5 \\
\hline Mean SF36 bodily pain & 41.2 & 40.6 & 41.4 & 42 \\
\hline Mean SF36 social role functioning & 34.1 & 33.8 & 34.2 & 35.4 \\
\hline \multicolumn{5}{|l|}{ Physician characteristics } \\
\hline$\%$ Female & 22.9 & 20.0 & 23.8 & 25.0 \\
\hline$\%$ White & 82.9 & 80.0 & 100 *** & 0 *** \\
\hline$\%$ African American & 14.3 & 10.0 & $0 * *$ & $100 * *$ \\
\hline \multicolumn{5}{|l|}{ Patient-physician dyad characteristics } \\
\hline Years patient seen this physician & 6.4 & 3.2 & $6.9 * *$ & $16.0^{* * * *}$ \\
\hline \multicolumn{5}{|l|}{ Time share of topics in visits $(N=392)$} \\
\hline Biomedical topics $(\%)$ & 78.6 & 73.7 & $81.2^{* *}$ & 81.9 \\
\hline Mental health topics $(\%)$ & 4.4 & 4.7 & 4.3 & 1.6 \\
\hline Personal habit topics $(\%)$ & 4.2 & 4.2 & 3.9 & 5.8 \\
\hline Psychosocial topics (\%) & 9.2 & 13.3 & $7.4^{* * *}$ & $5.6^{* * *}$ \\
\hline Patient-physician relationship topics $(\%)$ & 1.4 & 2.0 & 1.2 & 6.8 \\
\hline Other topics $(\%)$ & 2.2 & 2.0 & 2.0 & 4.4 \\
\hline \multicolumn{5}{|l|}{ Topic characteristics $(N=2,448)$} \\
\hline Biomedical topics $(\%)$ & 71.5 & 69.5 & 72.8 & 71.0 \\
\hline Mental health topics $(\%)$ & 2.9 & 3.7 & 2.43 & 1.9 \\
\hline Personal habit topics $(\%)$ & 6.6 & 5.5 & 7.0 & 9.7 \\
\hline Psychosocial topics $(\%)$ & 12.2 & 13.9 & 11.6 & 7.7 \\
\hline Patient-physician relationship topics (\%) & 2.7 & 3.4 & 2.4 & 2.6 \\
\hline Other topics $(\%)$ & 4.1 & 4.0 & 3.9 & 7.1 \\
\hline Patient initiated topics $(\%)$ & 44.3 & 52.0 & $40.2 * *$ & $38.1 * *$ \\
\hline Physician shown uncertainty $(\%)$ & 4.6 & 5.6 & $3.3^{* * *}$ & $9.7^{* * *}$ \\
\hline Patient shown uncertainty (\%) & 19.4 & 24.4 & $16.5^{\text {*** }}$ & $17.4 * *$ \\
\hline Patient shown nonverbal cue of mood disorder (\%) & 7.7 & 10.7 & $6.0 * * *$ & $5.2^{* * *}$ \\
\hline
\end{tabular}

*Significantly different from AMC, $p<.05$, **Significantly different from AMC, $p<.01$.

AMC, Academic Medical Center. 
counted for 3 percent of the topics while 4 percent of the topics were other topics including small talk. Bivariate statistics on all explanatory variables are presented in Table 1 by practice settings.

\section{Survival Analyses of Talk Duration}

Tables 2 and 3 show the results from the topic-level and visit-level analyses, respectively, expressed in hazard ratios (HRs). In Table 2, we present findings on the major topics and minor topics for comparison. Because no visits contained a major topic on the patient-physician relationship, that variable was not included in the analysis of major topics.

A HR $>1.0$ means that talk is more likely to end, i.e., the talk length is shorter, in comparison with the reference group for categorical variables and an increment in continuous variables. For statistically significant variables, we report a quantitative interpretation of their effects on duration of time according to equation (3) presented earlier. ${ }^{4}$

\section{Nature of Topics}

Patient Talk. The topic-level analysis showed that, in comparison with patient talk time on biomedical issues, patients talked 85 percent longer on a mental health issue $(p<.01)$ if it was the major topic, and 42 percent longer otherwise $(p<.01)$. They spoke the same length on a personal habit topic as on biomedical if it was the major topic, but 21 percent less otherwise $(p<.01)$. The reverse was true for psychosocial topics: 57 percent longer $(p<.01)$ versus no difference (Table 2). The visit level analysis showed that patients talked 1 percent longer in response to a 1 percent increase in the time share of topics on mental health or on psychosocial issues $(p<.01$; Table 3$)$.

Physician Talk. When mental health was the major topic, physicians talked no longer than on biomedical topics. When it was a minor topic, however, physicians talked 27 percent less $(p<.01)$ than on biomedical topics. Similarly, no difference for a personal habit issue as the major but talk was 40 percent shorter $(p<.01)$ otherwise. Physicians spent 28 percent less time on psychosocial topics $(p<.01)$ when they were major topics and 39 percent less time when they were minor topics (Table 2). At the visit level, no significant difference was found in physician talk time based on the time share of topics (Table 3).

Total Length of Topic or Visit. There was only one significant determinant of the length of topics: mental health topics were 37 percent longer than biomedical topics $(p<.01)$ when they were major topics and the same when 


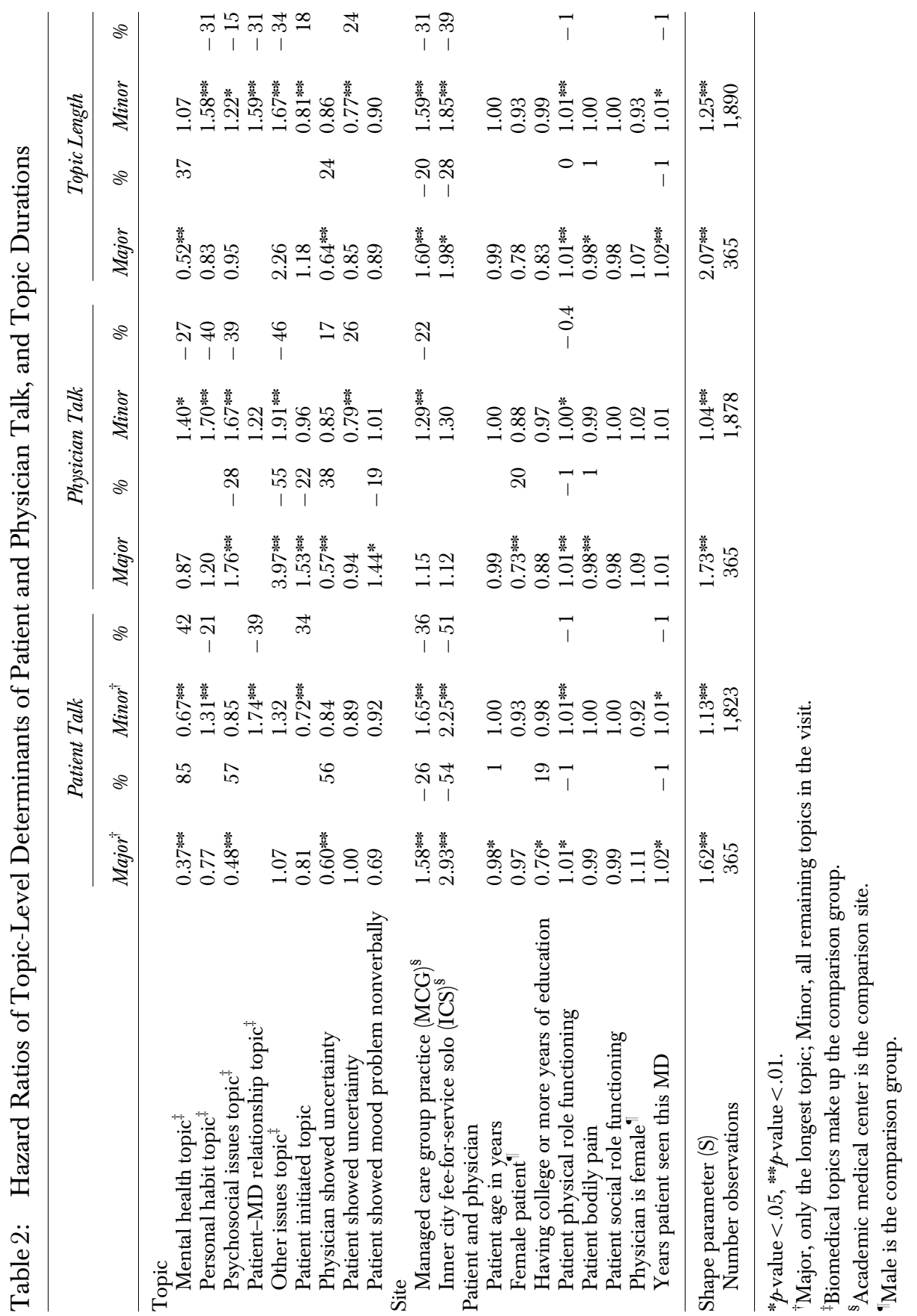


Table 3: Hazard Ratios of Visit-Level Determinants of Patient Talk, Physician Talk, and Visit Duration

\begin{tabular}{|c|c|c|c|c|c|c|}
\hline & \multicolumn{2}{|c|}{ Patient Talk } & \multicolumn{2}{|c|}{ Physician Talk } & \multicolumn{2}{|c|}{ Visit Length } \\
\hline & $H R$ & $\%$ & $H R$ & $\%$ & $H R$ & $\%$ \\
\hline \multicolumn{7}{|l|}{ Topic } \\
\hline Personal habit topic $(\%)^{\dagger}$ & 1.00 & & 1.00 & & 1.00 & \\
\hline Psychosocial issues topic $(\%)^{\dagger}$ & $0.98^{* * *}$ & 0.8 & 1.00 & & 0.99 & \\
\hline Patient-MD relationship topic $(\%)^{\dagger}$ & 1.01 & & 0.98 & & 1.00 & \\
\hline Other issues topic $(\%)^{\dagger}$ & $1.01 *$ & -0.7 & 1.01 & & 1.02 & \\
\hline Mental health topic $(\%)^{\dagger}$ & $0.99^{* * *}$ & 0.7 & 1.00 & & 1.00 & \\
\hline Patient initiated topic $(\%)$ & $0.99^{* *}$ & 0.4 & 1.00 & & 1.00 & \\
\hline Physician showed uncertainty $(\%)$ & $0.99 *$ & 0.3 & 1.00 & & 1.00 & \\
\hline Patient showed uncertainty $(\%)$ & 1.00 & & 1.00 & & 1.00 & \\
\hline $\begin{array}{l}\text { Patient showed mood problem } \\
\text { nonverbally }(\%)\end{array}$ & 1.00 & & 1.00 & & 1.00 & \\
\hline \multicolumn{7}{|l|}{ Site } \\
\hline Managed care group practice $(\mathrm{MCG})^{\ddagger}$ & $2.47 * *$ & -36.8 & $1.70^{*}$ & -22.7 & $2.89^{* * * *}$ & -32.5 \\
\hline Inner city fee-for-service solo practices $(\mathrm{ICS})^{\ddagger}$ & $6.58^{* * *}$ & -61.6 & 2.51 & & $3.24^{* * * *}$ & -35.4 \\
\hline \multicolumn{7}{|l|}{ Patient and physician } \\
\hline Age in years & 0.98 & & 0.90 & & $0.97 * *$ & 1.0 \\
\hline Female patient ${ }^{\S}$ & 0.95 & & $0.74^{*}$ & 16.1 & 0.91 & \\
\hline Having college or more years of education & 0.90 & & 0.90 & & 0.85 & \\
\hline SF36: physical role functioning & $1.01^{*}$ & -0.6 & $1.01^{* * *}$ & -0.4 & $1.01^{* * *}$ & -0.3 \\
\hline SF36: bodily pain & 0.99 & & $0.97 * *$ & 1.3 & $0.98^{* * * *}$ & 0.8 \\
\hline SF36: social role functioning & 1.00 & & 1.00 & & 1.00 & \\
\hline Female physician ${ }^{\S}$ & 0.87 & & 1.04 & & 0.74 & \\
\hline Years patient seen this MD & $1.02^{* * *}$ & -1 & 1.01 & & 1.01 & \\
\hline$s$ & $1.97^{* * *}$ & & 2.05 & & $2.69^{* * * *}$ & \\
\hline Number of observations & 366 & & 366 & & 366 & \\
\hline
\end{tabular}

$* p$-value $<.05,{ }^{* * *} p$-value $<.01$.

${ }^{\dagger}$ Biomedical topics make up the comparison group.

${ }^{\ddagger}$ Academic medical center is the comparison site.

${ }^{\S}$ Male is the comparison group.

they were minor topics. All other minor topics were shorter than biomedical topics (Table 2). At the visit level, time shares of topics did not affect length of visits (Table 3). These results suggest that intravisit time allocation across topics did not influence how long the visit lasted.

\section{Initiator of Topics}

Patient Talk. At the topic level, patients' talk length was not significantly influenced by their initiation of major topics. They spoke 34 percent longer, 
however, when they initiated minor topics $(p<.01)$. At visit level, the share of topics that were initiated by the patient had a small but significant effect: $(0.4$ percent longer, $p<.01$; Table 3 ).

Physician Talk. Physicians spoke 22 percent less during major topics initiated by patients $(p<.01)$ but no difference during minor topics. Initiation had no significant effect at the visit level (Tables 2 and 3).

Total Length of Topic or Visit. Initiation had no significant effects on major topics but patient initiation increased minor topic time by 18 percent. These results imply that, to make up for patients' longer talk, physicians spoke less when patients initiated a major topic. Consequently, neither the length of the topic nor of the visit was affected by patient's initiation of major topics. Patients, on the contrary, spoke more on minor topics that they had initiated and those topics were longer as a result.

Uncertainty and Cues of Mood Problem. Physician uncertainty was associated with 56 percent longer patient talk time $(p<.01)$ in major topics (Table 2$)$, and 0.3 percent longer $(p<.05)$ in the visit (Table 3$)$. When uncertain, physicians talked 38 percent longer $(p<.01)$ on major topics (Table 2$)$, and the major topics lasted 24 percent longer $(p<.01$; Table 2$)$. Patient uncertainty did not influence time on major topics but was associate with 26 percent longer physician talk time $(p<.01)$ and 24 percent longer topic length $(p<.01)$ on minor topics. As for cues of mood problem, physicians spoke 19 percent less with patients who showed nonverbal cues of mood problems during the major topics $(p<.05$; Table 2$)$. Expression of uncertainty did not increase total visit length.

\section{Physician Practice Setting}

Patient Talk. In comparison with the AMC, patients talked 26 percent less at the MCG $(p<.01)$, and 54 percent less at the ICS $(p<.01)$ during discussion over major topics. Similar effects were found among minor topics (Table 2). Visit-level results were similar with the MCG being 37 percent shorter $(p<.01)$, and ICS being 62 percent shorter than the AMC $(p<.01$; Table 3).

Physician Talk. Physician talk time did not differ significantly across sites during major topics but was 22 percent shorter among minor topics at the MCG. At the visit level, however, MCG physicians talked 23 percent less than AMC physicians $(p<.05)$. 
Total Length of Topic or Visit. Major topics were 20 percent shorter at the MCG $(p<.01)$ and 28 percent shorter at the ICS $(p<.05)$. Minor topics were even shorter at both MCG and ICS (Table 2). Visits were 33 percent shorter at the MCG $(p<.01)$ and 35 percent shorter at the ICS $(p<.01$; Table 3$)$.

\section{Patient, Physician Characteristics, and Length of Patient-Physician Relationship.} Patients with college level or higher education spoke 19 percent longer in major topics $(p<.05)$ but not on minor topics. Physicians spoke 20 percent longer to female patients during major topics $(p<.01)$ and 16 percent longer during visits $(p<.01)$. Physician gender had no effect on talk time.

\section{DISCUSSION}

This study offers several new findings with respect to the amount of time devoted to specific topics in office visits. We found that a very limited amount of time was allocated to topics. A median of only 5 minutes was spent on even the major topic in a visit. We also found that visit length was insensitive to the contents of a visit. Longer time spent on major topics seems to have been compensated by limiting the time allocated to minor topics, therefore leaving the visit length more or less the same. Determinants of topic length differed between major and minor topics. For example, if mental health was the major topic, the topic lasted longer than biomedical topics but was the same length as biomedical topics if it was a minor topic. Likewise, a physician's expression of uncertainty was associated with longer topic length if the topic was a major topic, not so if it was a minor topic. Further, macro factors related to practice settings, e.g., organizational structure and physician payment incentives, appear to have more influence on visit length than micro-within visit factors. Some implications on these findings are discussed below.

\section{Topics and Time Allocation}

Primary care visits indeed contain a large number of topics covering diverse subjects. With only about 2 minutes of talk time on even the major topic from each speaker, we could not help but wonder how much is accomplished during such a brief exchange. Future research should assess whether the amount of time for major topics or a particular type of topic was "sufficient" to facilitate effective information exchange and patientcentered care. 
While there are typically three to four biomedical topics raised in most visits (Braddock et al. 1999; Beasley et al. 2004), a broader definition of topics finds more subjects of discussion. All compete for visit time. Our most intriguing finding is that while time spent by the patient and physician on a topic responds to many factors, time of the visit overall is much less malleable. A physician could adjust to a patient's presentation of a timeconsuming problem by either extending the patient's visit and taking a little time away from the many other patients seen in the course of a day, or, keeping this patient's visit about the same by restricting time on other problems the patient might have. It appears from our data that the second strategy predominates. Therefore, if visit lengths are rigidly set, patients with more health concerns that would have required more time for history-taking and counseling could end up receiving less time than they need. Competing time demands during office visits may contribute to lower overall quality for vulnerable older people (Min et al. 2005) if physicians are less inclined to spend the time and cognitive energy to engage in these time-consuming processes.

Incentives in prevailing physician payments favor procedure-based patient care over time-intensive evaluation and management care. Much of what physicians do to help their patients during an office visit would be virtually impossible to be captured in a fee schedule or a pay-for-performance system. Further, psychosocial aspects of health and health care take time to address. For example, issues such as a pending move to nursing home, or a physician's retirement and the handing over of the patient to another physician, tend to be under-represented in medical records. Furthermore, some parts of the conversation aim at building rapport or easing tension, e.g., telling jokes. While most of these subjects do not require medical expertize, they occur frequently during office visits, and probably influence the effectiveness of communication. Overlooking their influence on how clinic time (hence physician effort and resources) is spent, however, may distort incentives for quality effort because they may well represent the emotional labor a physician is performing. As long as physicians are expected to relate to their patients in a personal and empathetic manner (Suchman 2006), they need to be given resources and incentives to develop and sustain such relationships. A payment system that offers physician flexibility in interaction content and time can be very desirable for providing patient-centered care. This could be a fruitful topic for future research, perhaps by sequential analysis of the topics. It could have implications on medical education and continuation of training in effective clinical time management. 


\section{Length of Visit and Practice Setting Effects}

The average visit length in our sample of elderly patients was 17.4 minutes (median, 16 minutes) - quite close to the visit lengths reported in previous studies (Braddock et al. 1999; Mechanic, McAlpine, and Rosenthal 2001), which included both elderly and younger patients. The variations in visit length across practice sites suggest that different patients get dissimilar treatments. Besides influences of financial incentives and organizational cultures (Wolinsky and Corry 1981; Hillman, Pauly, and Kerstein 1989), educational mission at the AMC could have caused visits at the AMC to be longer visits. Fortunately, we were able to examine the influence of medical students on the length of visits. A medical student was present in only 12 out of the 147 visits at the $\mathrm{AMC}$ and none were at the other practices. The median lengths of these 12 visits (24.8 minutes) were compared with the other 135 visits (23.0 minutes). While they differed by almost 2 minutes, the difference was nonsignificant.

Owing to the small number of sites in the study, however, we view the across site comparisons as descriptive only. Furthermore, findings about the inner city practices are more complex to interpret, due to the unique combination of exclusively African American patient-physician pairs.

In clinical practice today, it appears, visit lengths may be prescribed by physicians' practice settings. Physicians are often held to daily patient volume targets that can also limit the amount of time they spend with each patient. Hence, examining the length of visit may not provide much new information. This observation is supported by the results from our visit-level analyses, which show that the site indicator is the dominant determinant of time at the visit level. Future studies aimed at better understanding of patientphysician interaction can benefit from a more in-depth analysis as was done in this study.

\section{Influence of Patients}

Patients who initiated major topics were met with significant reduction in physician talk time during the major topic in the visit. This may suggest that physicians did not view those topics as important as patients did. Similarly, physician talked much less with patients when patients showed mood problems nonverbally. It raises a question about whether physicians feel disinclined to engage patients who appear depressed or anxious. Additional research should be pursued to examine the content and rapport of interaction in these topics. 
Similar to previous findings (Waitzkin 1985), patients with at least some college education spoke significantly longer during the major topic in a visit. This suggested that better-educated patients might have prioritized how they would use the visit time so that they could spend sufficient time on the topic that was most important to them. Other patients can be encouraged to plan ahead to make sure that they are heard on pertinent issues. Alternatively, physicians might be less inclined to cut off the talk of a patient with a higher socioeconomic status.

Probably the best-known work related to ours is Roter's Interaction Analysis System (RIAS; Roter 1977) which analyzes visits by coding "utterances," defined as complete thoughts expressed by the patient or physician. As one of the most widely used systems for analyzing patient-physician communication, RIAS provides a wealth of information based on aggregate utterance counts, on communication behaviors pertaining to data gathering, patient education and counseling, rapport building, and partnership building (Levinson and Roter 1995; Roter et al. 1997; Roter, Hall, and Aoki 2002). The RIAS is oriented to measuring and evaluating communication process (Wasserman and Inui 1983), rather than time or topics discussed, and thus serves a different purpose than our investigation. Our approach directly observes time pressure and competing demands within the visit coming from different issues facing the physician and patient, thereby offering new insights on patient-physician interaction.

This study has some limitations. For example, we do not have information from the medical records which could provide additional information on patient's history, nor do we have data on previous or subsequent visits. Further, the convenience sample limits the external validities of the findings. These limitations are often shared with other research on patient-physician interactions. Additional studies are needed to replicate the approach on other patient age groups and practice settings. The impact of such findings on clinical practice and policy will be stronger if consistent patterns are identified, using this innovative approach to examine how clinical time- - critical resource in health care-is used. Grounding research in the direct analysis of the conduct of patient and physician in the actual of units of clinical decision making, as done in this study, may be a promising approach for future studies.

\section{ACKNOWLEDGMENTS}

We thank Mary Ann Cook and Marcia Ory for the data, NIMH (MH01935) and NIA (AG15737) for funding the research, and Margarita Alegria, John Z. 
Ayanian, Howard Beckman, Richard Frankel, Rachel M. Henke, Richard Kravitz, Joseph Newhouse, Richard Street Jr., Suojin Wang, and two anonymous reviewers for helpful comments on an earlier version of the paper.

Disclosures: None.

Disclaimers: None.

\section{APPENDIX A. TRAINING OF CODERS}

Training of coders involved over 8 hours of initial didactic instruction, and independent coding of 10 training visits by each coder. Intercoder reliability was calculated after data on the 10 training visits were collected. An additional five training visits were chosen and coded by each coder in a second round of training to improve reliability.

To measure agreement among coders, we calculated intraclass correlation (ICC) for numerical variables. In light of debates on properties of Cohen's $\kappa$ and its susceptibility to showing low values for uncommon behaviors (Cicchetti and Feinstein 1990; Feinstien and Cicchetti 1990; Bakeman et al. 1997; Ickes, Marangoni, and Garcia 1997), we used both Cohen's $\kappa$ and percent agreement for categorical variables (Eide, Graugaard, and Finset 2004).

After the second round of training coding, consistency was satisfactory The ICC for visit length was 0.98 ; total talk time, 0.89 ; patient talk time, 0.84 ; physician talk time, 0.86; and number of topics, 0.95. The Cohen's $\kappa$ and percent agreement for patient showing verbal cue for mood disorder was 0.31 and 92 percent; for nonverbal cue for mood disorder was 0.10 and 90 percent, and for showing uncertainty, $0.06 / 82$ and $1.00 / 98$ percent on patient and physician's expression of uncertainty, respectively. Intrarater ICC ranged from 0.84 to 1 on number of topics, from 0.98 to 0.99 on all other numerical variables.

Following Braddock et al. (1999), we ensured interrater reliability by randomly selecting 10 percent of the visits to be recoded by a second coder. To ensure intrarater reliability 5 percent of the visits coded by each coder were selected for repeated coding by the same coder. Coding-related questions were resolved through weekly team consultations.

\section{APPENDIX B. DERIVATION OF QUANTITATIVE INTERPRETATIONS OF SURVIVAL ANALYSIS RESULTS}

To test duration dependence, we use the Weibull proportional hazard function (Cleves et al. 2004), at the topic level 


$$
h\left(t \mid \mathbf{x}_{i}\right)=h_{0}(t) \exp \left(\boldsymbol{\beta}^{\prime} \mathbf{x}_{i}\right)
$$

where $t$ is time in seconds; $\boldsymbol{\beta}^{\prime}=\left(\beta_{1}, \ldots, \beta_{j}, \ldots, \beta_{j}\right)$ is a parameter vector for covariates. $\mathbf{x}^{\prime}{ }_{i}=\left(x_{i 1}, \ldots, x_{i j}, \ldots, x_{i}\right)$ is a data vector; $\mathbf{x}_{i}$ represent topics, $i=1$, $\ldots, K$ where $K$ is the total number of topics; $j=1, \ldots, J$ is the index for explanatory variables. In equation $(\mathrm{B} 1), h_{0}(t)$ is the baseline hazard rate which can be modeled as

$$
h_{0}(t)=s t^{s-1} \exp \left(\beta_{0}\right)
$$

where $s$ and $\beta_{0}$ are parameters to estimate. $s$ is known as the shape parameter which represents the presence of duration dependence if it is different than 1 . $\beta_{0}$ is a scale parameter in Weibull model. The survival probability, i.e., the probability for a visit or topic lasting longer than time $t$, has the form

$$
S\left(t \mid \mathbf{x}_{i}\right)=\exp \left(-t^{s} \exp \left(\beta_{0}+\boldsymbol{\beta}^{\prime} \mathbf{x}_{i}\right)\right)
$$

The exponential of $\beta_{j}$ has an interpretation as a hazard ratio (HR) which is the change of hazard rate with 1 unit change in the value of the $j$ th covariate.

Suppose at time $t_{0}$ the survival probability is $S\left(t_{0} \mid \mathbf{x}_{0}\right)$, we want to find a time point $t_{1}$ such that the survival probability $S\left(t_{1} \mid \mathbf{x}_{1}\right)$ is the same as $S\left(t_{0} \mid \mathbf{x}_{0}\right)$, after 1 unit increase in the value of the $j$ th covariate. That is

$$
S\left(t_{0} \mid \mathbf{x}_{0}\right)=\exp \left(-t_{0}^{s} \exp \left(\beta_{0}+\boldsymbol{\beta}^{\prime} \mathbf{x}_{0}\right)\right)=\exp \left(-t_{1}^{s} \exp \left(\beta_{0}+\boldsymbol{\beta}^{\prime} \mathbf{x}_{1}\right)\right)=S\left(t_{1} \mid \mathbf{x}_{1}\right) .
$$

Solving for $t_{1}$, we have

$$
t_{1}^{s}=t_{0}^{s} \exp \left(\boldsymbol{\beta}^{\prime} \mathbf{x}_{0}-\boldsymbol{\beta}^{\prime} \mathbf{x}_{1}\right)
$$

where $\boldsymbol{\beta}^{\prime} \mathbf{x}_{0}-\boldsymbol{\beta}^{\prime} \mathbf{x}_{1}=\left[\left(\beta_{1} x_{01}+\beta_{2} x_{02}+\ldots+\beta_{j} x_{0 j}+\ldots\right)-\left(\beta_{1} x_{01}+\beta_{2} x_{02}+\ldots\right.\right.$ $\left.+\beta_{j}\left(x_{0 j}+1\right)+\ldots\right]=-\beta_{j}$.

Hence, we get $t_{1}^{s}=t_{0}^{s} \exp \left(-\beta_{j}\right)$ or $t_{1}=t_{0} \exp \left(-\beta_{j} / s\right)$ Because $\exp \left(\beta_{j}\right)=$ $\mathrm{HR}_{j}$, where $\mathrm{HR}_{j}$ stands for hazard ratio for the $j$ th covariate, we have

$$
t_{1}=t_{0} H R_{j}^{-1 / s}
$$

Interpretation of coefficients in the Weibull model as HRs is not straightforward. We evaluate the quantitative relationship between a change in covariates and The change in length of time at a constant survival probability. We 
can then calculate the percent change in talk time as a result of an increment in an explanatory variable, which is

$$
\% \text { change in talk time }=\left(t_{1}-t_{0}\right) / t_{0}=t_{1} / t_{0}-1=\mathrm{HR}^{-1 / s}-1 .
$$

Equation (B5) enables us to calculate, holding constant the survival probability, how changes in key explanatory variables would influence the length of time spent on a topic or a visit.

Note: equation (B1) here corresponds to equation (1) in the text, equations (B2)-(2), and (B5)-(3) in text.

\section{NOTES}

1. Nineteen of the visits were multiple visits between a few patient-physician dyads. Sensitivity analyses excluding these visits obtained similar results as the full sample. Results reported here are from all 392 visits.

2. Silences are meaningful social interaction activities that can convey multiple messages. For example, when diagnostic news is bad, silence may be a patient's exhibition of stoicism (Maynard 2003).

3. For example, in a visit covering five topics, two of them focused on biomedical issues. Their combined talk time was 450 seconds, out of a total of 1,020 seconds talk time in the visit. The time share of the biomedical content area would be 44 percent. If one topic was on mental health issues and it took 120 seconds, the share of mental health content time would be 12 percent, and so on.

4. For example, from Table 2, we see that, among the major topics, the hazard ratio of changing the topic from biomedical to mental health is 0.37 , and the estimate of shape parameter $s$ is 1.62 . We can calculate percent change in patient talk time by applying equation, $\mathrm{HR}^{-1 / \mathrm{s}}-1=(0.37)^{-1 / 1.62}-1=85$ percent. Therefore, patient's talk time on mental health topics is 85 percent longer than on biomedical topics conditional on a given survival probability.

\section{REFERENCES}

American Medical Association. 2001. Physician Characteristics and Distribution in the US. Chicago: American Medical Association Press.

American Psychiatric Association. 1994. Diagnostic and Statistical Manual of Mental Disorders DSM-IV, 4th Edition. Arlington, VA: American Psychiatric Association.

Bakeman, R., V. Quera, D. McArther, and B. F. Robinson. 1997. "Detecting Sequential Patterns and Determining Their Reliability with Fallible Observers." Psychological Methods 2 (4): 357-70.

Balsa, A. I., T. G. McGuire, and L. S. Meredith. 2005. "Testing for Statistical Discrimination in Health Care." Health Services Research 40 (1): 227-52. 
Beasley, J. W., T. H. Hankey, R. Erickson, K. C. Stange, M. Mundt, M. Elliott, P. Wiesen, and J. Bobula. 2004. "How Many Problems Do Family Physicians Manage at Each Encounter? A WReN Study." Annals of Family Medicine 2 (5): 405-10.

Bertakis, K. D., E. J. Callahan, L. J. Helms, R. Azari, and J. A. Robbins. 1993. "The Effect of Patient Health Status on Physician Practice Style.” Family Medicine 25 (8): 530-5.

Braddock, C. H. III, K. A. Edwards, N. M. Hasenberg, T. L. Laidley, and W. Levinson. 1999. "Informed Decision Making in Outpatient Practice: Time to Get Back to Basics.” Journal of American Medical Association 282 (24): 2313-20.

Charon, R., M. G. Greene, and R. D. Adelman. 1994. "Multi-Dimensional Interaction Analysis: A Collaborative Approach to the Study of Medical Discourse." Social Science and Medicine 39 (7): 955-65.

Cicchetti, D., and A. Feinstein. 1990. "High Agreement but Low Kappa: II. Resolving the Paradoxes." Journal of Clinical Epidemiology 43 (6): 551-8.

Cleves, M. A., W. W. Gould, and R. G. Gutierrez. 2004. An Introduction to Survival Analysis Using Stata. ${ }^{\mathbb{B}}$ College Station, TX: Stata Press, StataCorp.

Cook, M. 2002. Final Report: Assessment of Doctor-Elderly Patient Encounters, Grant No. R44 AG5737-S2. Washington, DC: National Institute of Aging.

Donabedian, A. 2005. "Evaluating the Quality of Medical Care." Milbank Quarterly 83 (4): 691-729.

Eide, H., V Quera, P. Graugaard, and A. Finset. 2004. "Physician-Patient Dialogue Surrounding Patients' Expression of Concern: Applying Sequence Analysis to RIAS.” Social Science and Medicine 59 (1): 145-55.

Federal Interagency Forum on Aging Related Statistics. 2000. Older Americans 2000: Key Indicators of Well-Being. Hyattsville, MD: National Center for Health Statistics.

Feinstien, A., and D. Cicchetti. 1990. "High Agreement but Low Kappa: I. The Problems of Two Paradoxes." Journal of Clinical Epidemiology 43 (6): 543-9.

Fiscella, K., S. Meldrum, P. Franks, C. G. Shields, P. Duberstein, S. H. McDaniel, and R. M. Epstein. 2004. "Patient Trust: Is It Related to Patient-Centered Behavior of Primary Care Physicians?" Medical Care 42 (11): 1049-55.

Gattellari, M., K. J. Voigt, P. N. Butow, and M. H. N. Tattersall. 2002. "When the Treatment Goal Is Not Cure: Are Cancer Patients Equipped to Make Informed Decisions?" Journal of Clinical Oncology 20 (2): 503-13.

Gilchrist, V. J., K. C. Stange, S. A. Flocke, G. McCord, and C. C. Bourguet. 2004. “A Comparison of the National Ambulatory Medical Care Survey (NAMCS) Measurement Approach with Direct Observation of Outpatient Visits." Medical Care 42 (3): 276-80.

Gill, V. T. 1998. "Doing Attributions in Medical Interaction: Patients' Explanations for Illness and Doctors' Responses." Social Psychology Quarterly 61 (4): 342-60.

Heritage, J., and D. Maynard. 2006. "Problems and Prospects in the Study of DoctorPatient Interaction: 30 Years of Research in Primary Care." Annual Review of Sociology 32: 351-74. 
Hillman, A. L., M. V. Pauly, and J. J. Kerstein. 1989. "How Do Financial Incentives Affect Physicians' Clinical Decisions and the Financial Performance of Health Maintenance Organizations?” New England Journal of Medicine 321 (2): 86-92.

Hsiao, W. C., P. Braun, D. Dunn, and E. R. Becker. 1988. "Resource-Based Relative Values. An Overview." Journal of American Medical Association 260 (16): 2347-53.

Ickes, W., C. Marangoni, and S. Garcia. 1997. "Studying Empathic Accuracy in a Clinically Relevant Context.” In Empathic Accuracy, edited by W. Ickes, pp. 282310. New York: Guilford Press.

Levinson, W., and D. Roter. 1995. "Physicians' Psychosocial Beliefs Correlate with Their Patient Communication Skills." Journal of General Internal Medicine 10 (7): 375-9.

Levinson, W., D. L. Roter, J. P. Mullooly, V. T. Dull, and R. M. Frankel. 1997. "Physician-Patient Communication. The Relationship with Malpractice Claims among Primary Care Physicians and Surgeons." Journal of American Medical Association 277 (7): 553-9.

Maynard, D. 2003. Bad News, Good News: Order in Everyday Talk and Clinical Settings. Chicago: University of Chicago Press.

Mechanic, D., D. D. McAlpine, and M. Rosenthal. 2001. "Are Patients' Office Visits with Physicians Getting Shorter?” New England Journal of Medicine 344 (3): 198204.

Min, L. C., D. B. Reuben, C. H. MacLean, P. G. Shekelle, D. H. Solomon, T. Higashi, J. T. Chang, C. P. Roth, C. J. Kamberg, J. Adams, R. T. Young, and N. S. Wenger. 2005. "Predictors of Overall Quality of Care Provided to Vulnerable Older People." Journal of the American Geriatrics Society 53 (10): 1705-11.

Mishler, E. G. 1984. The Discourse of Medicine, Dialectics of Medical Interviews. Norwood, NJ: Abex Publishing Corporation.

Roter, D. 1977. "Patient Participation in the Patient-Provider Interaction: The Effects of Patient Question Asking on the Quality of Interaction, Satisfaction, and Compliance." Health Education Monographs 50: 281-315.

Roter, D., and J. Hall. 2004. "Physician Gender and Patient-Centered Communication: A Critical Review of Empirical Research.” Annual Review of Public Health 25: 497-519.

Roter, D. L., J. A. Hall, and Y. Aoki. 2002. "Physician Gender Effects in Medical Communication: A Meta-Analytic Review." Journal of American Medical Association 288 (6): 756-64.

Roter, D. L., M. Stewart, S. M. Putnam, M. Lipkin Jr., W. Stiles, and T. S. Inui. 1997. "Communication Patterns of Primary Care Physicians." Journal of American Medical Association 277 (4): 350-6.

STATACorp. 2003. STATA Reference Manual. College Station, TX: STATACorp.

Suchman, A. L. 2006. "A New Theoretical Foundation for Relationship-Centered Care. Complex Responsive Processes of Relating." Journal of General Internal Medicine 21 (s1): S40-4.

Tai-Seale, M., R. Bramson, D. Drukker, M.-L. Hurwitz, T. Tai-Seale, M. Ory, J. Richard Street, and M. A. Cook. 2005. "Understanding Primary Care Physicians' 
Propensity to Assess Elderly Patients for Depression Using Interaction and Survey Data." Medical Care 43 (12): 1217-24.

Thompson, T., A. Dorsey, K. Miller, and R. Parrott. 2003. Handbook of Health Communication. Mahwah, NJ: Lawrence Erlbaum Associates Publishers.

U.S. Census Bureau. 2001. Current Population Survey, March 2000. Special Populations Branch, Population Division.

Waitzkin, H. 1985. "Information Giving in Medical Care." Journal of Health and Social Behavior 26 (2): 81-101.

Ware, J., M. Kosinski, and J. Dewey. 2000. How to Score Version 2 of the SF-36 Health Survey. Lincoln, RI: QualityMetric Incorporated.

Wasserman, R. C., and T. S. Inui. 1983. "Systematic Analysis of Clinician-Patient Interactions: A Critique of Recent Approaches with Suggestions for Future Research." Medical Care 21 (3): 279-93.

Wilson, K. G. 1993. The Columbia Guide to Standard American English. New York: Columbia University Press.

Wolinsky, F. D., and B. A. Corry. 1981. "Organizational Structure and Medical Practice in Health Maintenance Organizations." In Profile of Medical Practice, edited by D. Goldfarb, pp. 67-82. Chicago: American Medical Association.

Yawn, B., M. A. Goodwin, S. J. Zyzanski, and K. C. Stange. 2003. "Time Use during Acute and Chronic Illness Visits to a Family Physician.” Family Practice 20 (4): $474-7$. 